\title{
Éros PLATÔNICO E TRÁGICO no Grande SERTÃo: VEREDAS
}

\author{
GiLmário GuerReiro dA Costa
}

Universidade de Brasília

Universidade de Coimbra

\section{Resumo}

Examinam-se neste trabalho os elementos platônicos presentes no romance Grande sertão: veredas, de Guimarães Rosa. São extratos intertextuais tomados especialmente aos diálogos Banquete e Fedro. Concedemos relevo, nessa análise,ao papel do amor e da dialética ascensional em meio à escrita fragmentária do romance, que impõe ao tema mudanças significativas, aproximando-o de uma experiência trágica.

\section{Abstract}

In this paper we analyse the Platonic elements present in the novel Grande sertão: veredas, by Guimarães Rosa. These intertextual extracts come especially from the dialogues Symposium and Phaedrus. In this analysis, we focused on the role of love and the scala amoris through the fragmentary writing of this novel, which substantially changes this topic, approaching a tragic experience.
Palavras-chave: amor platônico; tragicidade; Guimarães Rosa

Keywords:

Platonic love; tragic;

Guimarães

Rosa 


\section{Encaminhamentos iniciais}

$\mathrm{O}$ artesanato intertextual do romance Grande sertão: veredas apresenta desafio considerável para os seus leitores, não apenas devido à multiplicidade dos seus planos, mas sobretudo pelo caráter bastante peculiar de sua inscrição na tradição artística de que hauriu parte considerável dos seus motivos narrativos. As referências literárias e filosóficas neles se divisam a cada quadra do romance, despontando a notável erudição do escritor. Semelhante constatação já instruiria admiração considerável. No entanto, ainda não residiria nesse nível as razões da força dessa obra, e sim no modo único e relativamente original da sua revisitação do passado. Os artifícios utilizados guardam todas as indicações de conduzir-se para os fios de uma intertextualidade alquímica, porque votada a transformar os elementos de que se serve em matéria em tudo diferente. Tal é o propósito de seu diálogo ora explícito, ora apenas insinuado, com a tradição fillosófica, em geral, e com o platonismo, em particular.

São diversos os motivos platônicos discerníveis em Grande sertão: veredas, dentre os quais sobressaem aqueles tomados às relações entre filosofia e amor, com que intenta conceder as imagens mais adequadas à relação entre o protagonista, Riobaldo, e Diadorim. Em um primeiro momento, cumpre revisitarmos esses traços do "amor platônico" para, em seguida, examinar como se metamorfoseiam no romance de Rosa. Um dos resultados dessa transformação será a de impingir elementos trágicos na concepção desse tópico - ou talvez de sublinhar uma tragicidade não de todo explícita na obra platônica.

\section{Amor, desejo e transcendência em Platão}

Divisa-se o problema do amor em momentos diversos da obra platônica. Para os fins a que nos propomos neste trabalho, concentramo-nos numa revisitação dos diálogos Banquete e Fedro, dos quais Guimarães Rosa toma parte considerável dos elementos que interessam à sua formulação artística desse tema. No que tange ao primeiro, interessa-nos o acento posto no afã de transcendência afim ao impulso erótico, e no último, as relações entre desejo e queda. Em um caso, a ascensão dialética, no outro, os riscos da queda, ainda que sob uma frágil promessa de redenção filosófica.

O Banquete enuncia sob ângulos diversos o desejo de transcendência inscrito no cerne de diversas experiências amorosas. Eros revela-se o intermediário na busca por atender aos móveis íntimos do desejo, em seu impulso com vistas ao objeto que se não tem, ou seja, no afã de suplantar os limites de uma situação de carência. A ascensão dialética proposta por Sócrates em seu discurso vai do amor pelos corpos belos, à compreensão do caráter superior da beleza da alma, rumo à apreciação da beleza das obras humanas.

Embora sob clara convicção da primazia do discurso filosófico sobre os demais, Platão constrói o seu diálogo com escrita acentuadamente poética. Tece os fios de uma cuidadosa elaboração artística, desde a cena preparatória inicial, com as suas histórias dentro de outras histórias, até as imagens ricas e conformes ao seu objeto. Desponta nesse itinerário a ênfase no amor enquanto impulso de transcendência, de que os discursos de Aristófanes e Sócrates oferecem algumas sugestões inesgotáveis. Em que pese às diferenças entre ambos, parecem compartilhar de uma pressuposto comum: a de que o princípio de complementaridade de si 
não repousa no indivíduo, mas no outro. $\mathrm{O}$ homem jamais basta a si mesmo, necessita sempre desse desvio ora prazeroso, ora incômodo, em direção ao outro, que Eros incentiva com todas os seus recursos. Seja o mito aristofânico, seja o de Diotima, enunciado por Sócrates, o sublinham. $\mathrm{O}$ arremate desse movimento, no entanto, é bastante diverso nos dois discursos. A essa análise acrescentaremos, na seção seguinte, uma reflexão breve sobre o discurso de Alcibíades, em diálogo com a provocativa leitura proposta por Martha Nussbaum.

No mito narrado por Aristófanes em seu discurso, a nostalgia da totalidade habita nos recessos da interioridade do homem: "Ora, quando a forma natural se encontrou dividida em duas, cada metade, com saudades da sua própria metade, se lhe reunia." (PLATÃO, 2010, 191a, p. 53). Um pouco adiante, acrescenta: "Dessa época longínqua data, sem dúvida alguma, a implantação do amor entre os homens - o amor que restabelece o nosso estado original e procura fazer de dois um só, curando assim a natureza humana." (PLATÃO, 2010, 191d, p. 54). $O$ amor a que se refere e acerca do qual discursa não se esgota numa mera união sexual: trata-se do anelo de um pela alma do outro, de forma que os dois possam ser um só. O outro torna-se em princípio de complementaridade de si mesmo, ou ainda, a alteridade amorosa descerra o caminho para o reencontro de si. Em sentido semelhante, observa Werner Jaeger: "O amor por outro ser humano é aqui focalizado à luz do processo de aperfeiçoamento do próprio eu. Esta perfeição só é atingível na relação com um tu.” (JAEGER, 1995, p. 732).

A intervenção de Aristófanes implica assim um ponto de virada, pois não mais se serve da oposição entre amor virtuoso e vulgar, como foi recorrente nos discursos dos personagens que lhe antecederam. Concebe-o agora como uma única aspiração comum a todos os homens, o desejo de totalidade: "The break, then, is to see love, not sundered into good and bad, but as a single aspiration, common to all, and directed (despite differences of sexual orientation) at the same generic object - wholeness" (FERRARI, 1992, p. 251-2). Movimenta-se nessa alegoria uma análise profunda da alma humana. Parece-nos que esse desejo de totalidade sugere a presença inesperada de elementos dionisíacos no diálogo platônico, na busca de uma unyo mystica que supere o princípio de individuação. Que seja enunciada pelo mestre da comédia, que tem em Dioniso sua divindade tutelar, oferece alguns indícios para a sustentação dessa hipótese.

Por seu turno, o mito do nascimento de Eros, narrado por Sócrates, segundo a narração que ouviu de Diotima, sublinha o seu poder enquanto intermediário (PLATÃO, 2010, 202e, p. 70). Em sendo filho do Recurso de da Pobreza, encontra-se na travessia entre a sabedoria e ignorância, mas não lhe é dada a possibilidade de oferecer a plenitude. Sua prerrogativa é a de instilar o desejo e incômodo com a carência que o constitui, com vistas à sua transcendência. Eleva-nos em direção à universalidade e à beleza. Por conseguinte, movemo-nos em direção ao outro e à filosofia por força do amor. Esse arremate segue uma fecunda relação entre seu o caráter "faltante"/carente e a filosofia: "e quem se não crê destituído não aspira, consequentemente, a um bem de cuja falta se não apercebe." (PLATÃO, 2010, 204a, p. 72). Conforme o enunciou uma estudiosa do diálogo, encena-se nesse discurso a tensão entre o que se é e o que se pretende ser, uma impulso, destarte, de transcendência (AZEVEDO, 2010).

$\mathrm{O}$ amor é amor do bom e do belo. Sócrates concorda com Agatão, que discursara antes dele, neste passo. Mas isso não implica ser o amor bom. Ele é desejo, e o desejo dirige-se a algo que se não tem. G. R. F. Ferrari sugere que o passo seguinte, com a narrativa de Diotima, 
permitirá a retomada, embora com feição própria, de diversos elementos dos discursos anteriores (FERRARI, 1992). O amor não é um deus, mas um intermediário, um daimônio. Não possuir a beleza e o bom não faz dele nem feio, tampouco mau. Tampouco lhe é dada a sabedoria, mas é um amante da sabedoria. O diálogo com Aristófanes coloca-se nestes termos: o amor efetivamente revela uma busca por aquilo que se perdeu. Equivoca-se, no entanto, ao identificar o que se teria perdido: não é a totalidade, mas o bem (FERRARI, 1992).Deve-se ainda acrescentar que o amor não é apenas amor do bem, mas sobretudo de possuí-lo para sempre. Revela, por essa via, o desejo do bem e da imortalidade. Ao procriar, um homem torna seus filhos herdeiros da sua memória e nome. Algo semelhante ocorre quando, ao amar jovens belos de corpo e caráter, neles instila o gosto por belos discursos e pelas virtudes cívicas.

Em passagem breve de um artigo, C. D. E. Reeve sustenta uma hipótese instigante: os diversos discursos do Banquete seriam, em grande medida, imagens ilusórias do amor; guardariam sua parcela de verdade enquanto parte da Beleza, mas não seriam nada além disso (REEVE, 2006, p. 296). Essa proposta de leitura conserva a vantagem de salientar o quanto a materialidade dos discursos serve a um estratagema filosófico.

Ganha relevo, nesse sentido, um traço por vezes comum ao amor e à escrita: ambos delineiam o discurso de uma ausência, porque movidos pelo desejo. O Banquete concede dupla forma a isso, vincada em temporalidade: em Aristófanes, com a cena inaugural de uma separação cujos despojos a memória colhe em nostalgia; em Sócrates, com o nascimento ambíguo de Eros, filho de um afã eterno, mas também de uma carência constitutiva, figura do tempo.

No que tange ao Fedro, a passagem em que se de descreve o impulso da alma em direção à beleza é de rara penetração psicológica. Todos os indícios de uma reflexão sobre o efeito da arte, ou ao menos da beleza a ela relacionada, aí se divisam. Na visão da beleza da pessoa amada, as asas do amante, outrora constitutiva das almas, tornam outra vez a crescer. Discurso ele mesmo belo. Também sublinha a concepção platônica de inteligência, noûs, que não se restringiria a uma operação racional, pois pressupõe também o concurso do pensamento e do desejo, conforme o esclarece um comentador do diálogo: "But võ̃ $\varsigma$ in Plato is not mere intellect divorced from passion and desire, as a superficial reading of Phaedo and Republic might perhaps lead us to suppose; it is reason or thought moved by desire, by the desire of the soul for that is akin to it." (HACKFORTH, 1952, p. 10).

Logo no início do Fedro se apresenta o liame entre amor e desejo, crucial não apenas ao entendimento platônico da questão, mas da sua concepção mesma de homem: "Ora, que o amor constitui um desejo é conhecido de todos." (PLATÃO, 2009, 237d, p. 44). A relação entre desejo e privação já estava presente em diversas passagens do Lísis, em especial nesta: Sócrates pergunta: "Mas, na verdade, o que deseja, deseja aquilo de que sente privado, não é?" (PLATÃO, 1980, 221d, p. 70). Trabattoni apresenta apropriadamente esse tópico ao entrever, no cerne dessa reflexão platônica,o liame entre tensão e desejo, o que sustentaria a perspectiva da vida enquanto impulso ao objeto que se não tem (TRABATTONI, 2010).

Diferentemente do Banquete, Sócrates agora afirma que o amor é Deus. O que explicaria a mudança na caracterização da sua natureza? Hackforth afirma que Sócrates o faz com vistas a salientar o aspecto progressivo da busca amorosa: "The 'daemonic'or immediate nature of Eros is simply the mythical way of expressing that to love is to make a progress from want to 
satisfaction, from misery to bliss, from ignorance to knowledge or wisdom." (HACKFORTH, 1952, p. 55). Além disso, no caso do Fedro, interessava o acento posto na possessão divina (HACKFORTH, 1952), elo que une momentos diversos da argumentação socrática.

O mito dos cavalos alados oferece imagem adequada e poética a essas reflexões. Como é tarefa ingente referir a natureza da alma, pode-se no entanto dela aproximar-se num exercício mais afim às possibilidades humanas de conhecimento, mediante o recurso às semelhanças. Tal observação deixa ver a importância das símiles e metáforas no artesanato do conhecimento (PLATÃO, 2009, 246a-b, p. 60-1). Os dois cavalos tem, no homem, natureza oposta: um é manso, e lhe obedece sem custo; o outro, ao invés, é rude e insubmisso. Não se pode negar a intuição profunda dessa imagem, em que a alma humana se bate contra impulsos diversos, sendo a tarefa da educação filosófica a busca por oferecer a melhor ordenação possível a esse jogo incerto. Pode-se indagar se esse projeto não teria também a sua parcela de desejo, e assim o aceno em busca do que não se tem - o controle da suposta parte superior da alma.

Em um trecho rico em imagens e sugestões interpretativas, Sócrates, em seu segundo discurso, na palinódia ao amor, sustenta ser a alma imortal, e lhe são inerentes as asas, mas quando as perde, agarra-se a algo sólido, em sua queda, e o faz movimentar-se (PLATÃO, 2009, 246c, p. 61). As marcas do divino são a beleza e bondade. É dessas qualidades marcadas pela excelência que se nutre a alma; na escassez dessas qualidades, não obstante, deita a perder as asas, e então se precipita em queda: "Dessas excelências (o bom e o belo (precisamente se alimenta, e sobretudo cresce, o aparelho alado da alma, enquanto pelo vício, pelo mal e por tudo o que é contrário àquelas qualidades se degrada e perece." (PLATÃO, 2009, 246e, p. 62).

A contemplação da beleza faz a muitos, possuídos pelos deuses, desejarem voar. As suas asas tornam a crescer, mas ainda não dispõem de força suficiente para alçarem voo (PLATÃO, 2009, 249d-e, p. 66). Em passagem que não passa despercebida aos leitores de Platão, Riobaldo, protagonista do Grande sertão: veredas, assim expressa o amor que lhe arrebata a alma, movido por Diadorim: "O amor, já de si, é algum arrependimento. Abracei Diadorim, como as asas de todos os pássaros" (ROSA, 1994, p. 32). Esta passagem é acentuadamente trágica, em perspectiva não de todo explícita na palinódia socrática. Em ambos os casos, não obstante, a memória e a perda inscrevem seus traços. Em Platão, na nostalgia de um estado superior; em Riobaldo, na dívida trágica do passado.

$\mathrm{O}$ afã de transcendência despertado no amor, segundo as múltiplas reflexões do Fedro, assemelha-se, em alguns traços, ao Banquete. A razão de a beleza despertar o desejo de transcendência deve-se à reminiscência das verdades íntimas do Ser que todas as almas, em alguma momento, viram quando ainda não haviam decaído. Dentre todas as visões excelsas que a alma contemplou, a beleza distinguia-se por seu brilho. Daí que, ao vislumbrá-la nos objetos sensíveis, seu fulgor faz-nos relembrar de nossa origem divina:

Pois agradeça-se tudo isso à reminiscência; foi devido a ela que, com saudade do passado, falámos agora mais longamente. Quando à beleza, como foi dito, brilhava na sua realidade entre aquelas visões; chegados aqui abaixo, temo-la surpreendido, resplandecendo em sua mais luminosa clareza, através do mais clarividente dos nossos sentidos. A visão é, de facto, a mais aguda das sensações que nos chega através do corpo; mas não consegue ver o pensamento. (PLATÃO, 2009, 250d, p. 67).

No artigo de Reeve supramencionado, sustenta-se que o amor, em Platão, centra-se na figura de Sócrates, em sua capacidade de sedução e ensino, observável nos três diálogos 
eróticos, Lisis, Banquete e Fedro (REEVE, 2006). Examina um momento do Banquete em que Sócrates afirma ser um especialistana arte do amor. Como compreender semelhante afirmação? A resposta radicaria no liame etimológico supostamente existente entre eros, "amor", e erotan, que significa "fazer perguntas". Reside no vínculo dessas significações a base do reclamo socrático:

In fact, the claim is a non-trivial play on words facilitated by the fact that the noun eros ("love") and the verb erotan ("to ask questions") sound as if they are etymologically connected, a connection explicitly exploited in the Cratylus (398c5-e5). Socrates knows about the art of love in that - but just insofar as - he knows how to ask questions, how to converse elenctically (REEVE, 2006, p. 294).

Observa-se algo semelhante no Lísis. A certa altura (210E), Sócrates sustenta que se deve questionar o amante, em vez de mimá-lo. Um dos temas precípuos do diálogo é o desejo, por natureza vazio. No cerne dessa argumentação, desponta o projeto de formação do filósofo. O caminho levará o amante, por meio de questionamentos sucessivos, a estar cônscio da sua ignorância, etapa preparatória do filosofar: "The elenchus is important to love, then, because it creates a hunger for wisdom, a hunger which it cannot itself assuage" (REEVE, 2006, p. 295). Destarte, a arte do amor (tá erotica) associa-se intimamente à persuasão, ao tentame de convencer o amado a retribuir o afeto a ele dedicado.

Em caminho bastante diferente, Seth Bernadette, ao referir-se ao discurso de Aristófanes, sustenta que nele se narra uma "perda eterna", cujas promessas de superação mediante o reencontro amoroso nada mais seriam que ilusão: "there is no possibility of discovering the other half of our individuality. That is forever lost (...) Aristophanes seems to imply, therefore, that this feeling that out there somewhere there is our soul-mate is an illusion." (BERNADETE, 2000, p. 174). Move eros um sentimento de orgulho, de recuperar a sua metade, com a qual, em sua totalidade primeva, opunha-se aos deuses, desafiando-os com destemor. Seu impulso sugeriria um desejo de voltar ao poder. A cena política delineia um substituto imperfeito daquele assalto inicial ao céu - desejo de assenhorear-se do poder dos deuses, um impulso cósmico. Pode-se, no entanto, objetar que no cerne das conjecturas platônicas acerca desse questão encontra-se a figura da dúvida, do questionamento. Pode-se talvez conceder que em sua origem, Eros vê-se impelido pelo orgulho, pela presunção de ombrear com o poder dos deuses. Após o castigo, porém, nele predomina a humilde consideração dos seus limites e fragilidade. Bem pode ser o caso de que a insubordinação original de Eros vinque as marcas de uma insubordinação política assente na natureza íntima do amor.

A dúvida se nos afigura, nesse sentido, a contraparte de Eros: o ceticismo genuíno é uma sorte de erotismo. Faz corresponderem o estremecimento do corpo e os dilemas da alma. Não surpreende que o erotismo em Grande sertão: veredas ande a par com a dúvida. O mesmo Riobaldo que diz: "Eu quase que nada não sei. Mas desconfio de muita coisa" (ROSA, 1994, p. 16) e "Vivendo se aprende; mas o que se aprende, mais, é só a fazer outras maiores perguntas" (ROSA, 1994, p. 264), é o mesmo que suspira: "Diadorim é a minha neblina" (ROSA, 1994, p. 21) Crítica e erotismo comungam da desestabilização que impõem ao sujeito, obrigando-o a sair de si, assim abalando as suas certezas mais queridas - ou tão somente cômodas. Riobaldo descobriu assimetrias no mundo: havia respostas em demasia, não raro 
alimentando os sonhos mais tirânicos. Busca corrigir tais ilusões mediante a apresentação de indagações diversas, sem precipitar-se em exibir soluções, a não ser sob a forma da provisoriedade. Parece lidar com o seu interlocutor, e mesmo com os seus leitores, como a figura do perfeito amante socrático: dedica-se a narrar seu passado não por haver descoberto a verdade de si, mas precisamente por desconfiar da verdade, que se ausenta com tanta frequência, a exemplo do ser amado. Outrossim há nesse romance duas séries de discurso afins a esse tópico: um deles refere-se a Diadorim, o outro lida com o "diálogo" com o interlocutor de Riobaldo. Em ambos os casos, sublinha-se a partilha da ignorância de Riobaldo, cujo signo por excelência é o amor.

\section{Eros e fragilidade}

Martha Nussbaum inicia o estudo dedicado ao Banquete com a retomada de aspectos históricos da vida de Alcibíades, que serve à estratégia de ater-se a pormenores sutis no diálogo que convidariam a relê-lo a partir do pano da fundo de elementos biográficos dessa personagem (NUSSBAUM, 2001, p. 166). A argumentação da autora assim se estrutura: revisita uma acusação recorrente a Platão, a de que a sua teoria do amor ocupou-se com qualidades abstratas, em vez de deter-se em pessoas concretas, com a sua totalidade, a incluir características que estariam longe de quadrar com a exigência do bem e do belo expressos no discurso de Sócrates. Gregory Vlastos é um dos autores que apresentou semelhante críticaa qual, segundo lhe parece, pontuaria uma falha incontornável nessa teoria platônica. A contraargumentação de Nussbaum vai no sentido de ligar importância ao discurso de Alcibíades, que enuncia sua atração pela concretude e totalidade de Sócrates. Tal a razão de examinar diligentemente essa personagem em seu texto (NUSSBAUM, 2001, p. 167).

A autora tira uma consequência percuciente da urdidura textual do diálogo. A montagem sofisticada de histórias dentro de histórias sabe a mistérios. Disso decorreria o assesto da fragilidade do nosso saber acerca do amor: "The distancing, continually present to us in the indirect-discourse constructions of the Greek, makes us always aware of the fragility of our knowledge of love, our need to grope for understanding of this central element of our lives through hearing and telling stories" (NUSSBAUM, 2001, p. 168). Outra consequência revelaria que nem sempre os discípulos de Sócrates seguem o seu ensino - enfrentando a scala amoris em busca de padrões cada vez mais abstratos de conhecimento e virtude. Movem-nos, não raro, o apreço pela particularidade de uma história. Eis a razão por que o diálogo seria antes a história de Alcibíades, que a exibição do ensino socrático (NUSSBAUM, 2001, p. 168). Parece-nos, entretanto, ser possível comprometer-se com outra hipótese: o confronto entre ambas as perspectivas, a abstração socrática e a "paixão pelo particular" que move Alcibíades, talvez represente a impossibilidade de uma imagem perfeita e cabal acerca do amor. A palavra final acerca dele é a do inacabamento. No limite, de uma tensão afim ao trágico. Além disso, o diálogo como um todo não é sobre o discurso de Sócrates ou de Alcibíades - mas sobre a própria linguagem do amor, sobre a sua escrita, imersa em distanciamento e paixão, memória e esquecimento, ausência e presença.

O nome "Diotima" significaria "honra de Zeus". Segundo Nussbaum, trata-se de uma contraposição ao nome de uma cortesã de Alcibíades, Timandra (honra de um homem), a 
assinalar deste modo a diferença entre o foco que orienta as ações de ambos, Sócrates e Alcibíades: a amante do primeiro ocupava-se fundamentalmente de questões do espírito, diferente das do ultimo, cujo fascínio residia nos prazeres do corpo (NUSSBAUM, 2001, p. 177). A autora colhe dessa passagem algumas conclusões importantes, embora um tanto difíceis de sumariar. No diálogo, Platão deriva a fama (ficcional) de Diotima da salvação que ofereceu à cidade de Atenas, ao postergar o flagelo da peste por dez anos (201d). Os grandes benefícios para a cidade apenas o ofertaria quem se desfizesse da atitude autocentrada em busca de honrarias (NUSSBAUM, 2001, p. 177). Ressai aqui a necessidade de um despertar da situação em que nos encontramos, carente de sermos salvos desse apreço excessivo por nossos próprios interesses e honrarias.

O discurso de Alcibíades não lida com definições e explicações gerais sobre a natureza do amor. Antes, interessa-lhe narrar uma história sobre sua paixão por um indivíduo particular, Sócrates. No acume do discurso, serve-se de expressão de caráter trágico, pathonta gnõmai: "The concluding words of his speech are the tragic maxim pathonta gnõmai, 'understanding through experience' or 'suffering'" (NUSSBAUM, 2001, p. 185). A autora também distingue os tipos de aproximação a esse tema, oferecidos por Sócrates e Alcibíades. Em Sócrates, persiste a centralidade da epistéme, cujo objeto último são os universais abstratos: "Socrates claims to have epistemeof erotic matters (177D); and Socratic episteme, unlike Alcibiades' pathonta gnõmai, is deductive, scientific, concerned with universals" (NUSSBAUM, 2001, p. 186). Alcibíades, diferentemente, estriba-se na particularidade da sua história: "Socratic philosophy, then, cannot allow the truths of Alcibiades to count as contributions to philosophical understanding" (NUSSBAUM, 2001, p. 186).

A contraposição entre Sócrates e Alcibíades aproxima-se do arremate, com uma análise do seu impacto sobre a nossa capacidade de escolha entre as duas propostas. Por um lado, Alcibíades nos ofereceria um mergulho na particularidade, cuja concretude tem o mérito de acolher nossas necessidades mais evidentes, mas ao preço de renunciar à inteligibilidade do fenômeno amoroso; Sócrates, por seu turno, detém-se no nível da episteme, dos contornos inteligíveis desse fenômeno, embora ao fim lhe ausente precisamente os móveis do pensamento acerca do amor - os objetos concretos. Ficamos, segundo a autora, perante um conflito de jaez trágico, para o qual toda escolha resulta ilusória (NUSSBAUM, 2001, p. 198). Trata-se de uma reflexão difícil acerca do estatuto ambíguo do pensamento filosófico - ao menos em termos platônicos. Oferece-nos luz e inteligibilidade, mas ao preço de tornar pouco efetiva, ou carente de relevância, a intervenção no mundo, por exemplo. Há ainda, a nosso ver, um outro conflito, algo dramático: entre os reclamos de atemporalidade e ascensão dialética do pensar, em busca da apreensão pura das essências, e a própria inscrição temporal e material dos diálogos platônicos - sua intervenção concreta no mundo pela linguagem. Semelhante arrazoamento interessa ao diálogo com o Grande sertão: veredas. De que teor é o amor nesse romance? Focaliza a totalidade de Diadorim, embora sob a efígie do erro de leitura e da escrita fragmentária? É o que convém seguir agora.

\section{Eros nos desvios e travessias do sertão}

Suzy Sperber apresentou em um dos seus trabalhos ressalvas com respeito ao diálogo da 
obra rosiana com a filosofia. Suas observações guardam reparos metodológicos recomendáveis. A peculiaridade da narrativa rosiana instrui a cautela de se atentar para os modos como metamorfoseia com feição própria os elementos da tradição filosófica que escolhe incorporar enquanto estratégia intertextual. $O$ conhecimento em Rosa, mais especificamente no Grande sertão: veredas, jamais se desencarna em ideias abstratas. Passa sempre pela concretude do corpo e os desvios da memória, que não são meros instrumentos para a ascensão transcendente, mas o espaço e tempo da transformação. Provisoriedade e mistura são signos recorrentes na obra. Na elaboração artística do romance, Rosa serve-se das ideias filosóficas enquanto elementos propícios a fazer avançar seu artesanato linguístico: "A leitura dos pensadores, por parte de João Guimarães Rosa, ainda que the tenha dado o conhecimento de suas filosofias, foi aproveitado, sobretudo a partir de seus estímulos para a elaboração da linguagem e das imagens" (SPERBER, 2009, p. 146).

Benedito Nunes escreveu um ensaio que já se pode considerar clássico nesse tipo de estudos acerca de Guimarães Rosa (2009), e no qual parece atento aos riscos apontados por Sperber. Oferece estudo bastante sensível e com múltiplos planos interpretativos. Sobressai a proposta de articulação entre três personagens com quem o protagonista do romance, Riobaldo, entretém algum tipo de expressão amorosa: Diadorim, um amor "primitivo e caótico" (NUNES, 2009, p. 138); o de Nhorinhá, sensual e voluptuoso; e Otacília, que assume feição acentuadamente espiritual. Parecerá ao autor desdobrar-se em semelhante tríade os motivos da dialética ascensional do Banquete. Esse romance mistura em seu cadinho experimental elementos afins ao platonismo, a ele acrescentando tópicos provindos da mística heterodoxa:

a tematização do amor, na obra de Guimarães Rosa, repousa principalmente nessa ideia mestra do platonismo, colocada, porém, numa perspectiva mística heterodoxa, que se harmoniza com a tradição hermética e alquímica, fonte de uma rica simbologia amorosa (NUNES, 2009, p. 138-9)

É importante sublinhar que semelhante percurso rosiano assume a defesa da conservação do carnal no espiritual, numa complementaridade tal de que resulta a compreensão das relações sexuais isenta de lastros pecaminosos (NUNES, 2009, p. 149). Nessas sendas descerra-se uma concepção a uma só vez poética e filosófica de mundo que subjaz ao Grande sertão: veredas, e que pode ser sumariadanos termos ousados de Afonso Ávila: "uma aventura ético-erótica de configuração platônica." (ÁVILA, 2009, p. 274). Pode-se avançar ainda outra hipótese: a de que às promessas da ascensão dialética juntam-se os riscos do trágico e da perda, que se insinuam nas memórias do narrador-protagonista do romance.

Em A origem do drama barroco alemão, de Walter Benjamin, há passagens cuja meditação acerca da memória é intensa. Tomemos como exemplo o trecho:

A crítica é a mortificação das obras. Mais que quaisquer outras, as obras do Barroco confirmam essa verdade. Mortificação das obras: por conseqüência, não, romanticamente, um despertar da consciência nas que estão vivas, mas uma instalação do saber nas que estão mortas. A beleza que dura é um objeto do saber. Podemos questionar se a beleza que dura ainda merece esse nome; o que é certo é que nada existe de belo que não tenha em seu interior algo que mereça ser sabido. A filosofia não deve duvidar do seu poder de despertar a beleza adormecida na obra. (BENJAMIN, 1984, p. 203-4) 
Todo um trabalho da memória se descerra no ofício de ressuscitar a beleza adormecida. Não está excluída a possibilidade de se despertarem monstros juntamente com a jovem que sonha alheia ao tumulto do mundo. Talvez sejam os seus sonhos precisamente mais tumultuados do que se julga. O desadormecer a retira do terror onírico e a devolve ao assombro da vigília, tornando-se difícil saber o que resultaria menos doloroso. Nesse caso, não apenas "o sono da razão produz monstros" (Goya). A memória pulsa ambiguidade quando divisa algo de noturno e pavoroso também nos meandros mais iluminados da razão, resultando vão o tentame de lhe dissolvermos as sombras, as quais, não raro, num gesto de teimosia irônica, retornam agigantadas.

Guimarães Rosa urde semelhante preocupação quando escreve Grande sertão: veredas, que tem como um dos seus motivos recorrentes a memória, cuja tematização dá-se a partir dos desencontros do protagonista, Riobaldo. Um desses desencontros é o amoroso. Memória e amor são inseparáveis nessa narrativa. $\mathrm{O}$ amor não assume a promessa de absoluto que há no romantismo, mais especificamente em Tristão e Isolda, de Richard Wagner. Parece mais afim a uma experiência de finitude.

O amor de Riobaldo opera em triplo nível de negatividade: 1. A linguagem com a qual descreve Diadorim. 2. O caráter pervertido de que lhe parecia revestir-se sua paixão: ele julgava ser ela um homem. Tem um falso alívio quando, depois de morta, descobre-lhe o sexo. Falso porque ele bem o sabe, amou o homem que supunha ser Diadorim. A ilusão e o erro de leitura atravessam não apenas o amor de Riobaldo, mas todo o Grande sertão. 3. A própria construção do nome "Diadorim". Sua etimologia sugere a junção da partícula disjuntiva "dia" com o substantivo "dóros", (dom, dádiva), ambos de origem grega. A partícula "im" se ligaria a sufixação de um diminutivo carinhoso ${ }^{2}$. Todo esse jogo configura Diadorim numa perspectiva erradia, um dom que, num movimento um tanto paradoxal, nunca se dá efetivamente. Trata-se de personagem cifrada sob o signo da perda e da dispersão, sem o encontro com o absoluto, efeito lisérgico do amor. Nietzsche já observara a "ironia trágica que constitui a essência do amor." (NIETZSCHE, 1999, p. 13) Guimarães Rosa a isso acrescenta algumas notas melancólicas.

Mas Diadorim não obriga apenas a um transtorno amoroso: o passado é reescrito, não com vistas ao esclarecimento, mas como efígie de um sintoma: "Diadorim é a minha neblina" (ROSA, 1994, p. 21), diz Riobaldo a certa altura. A imagem é romântica apenas na aparência, pois o traço semântico difere do pressentimento do absoluto: Diadorim é o nome de uma perda, de uma fissura. É por causa dela que Riobaldo não pode reencontrar o passado.

Os desencontros que acompanham a escrita da memória devem-se a uma concepção não instrumental de linguagem e a uma resistência à reificação do homem. Riobaldo vê escapar o passado, do qual a memória lhe celebra as exéquias, porque não há uma origem identificada e estável à qual se possa remeter entes e pessoas e dizer: "assim eram as coisas", "isto era Diadorim", "este era eu". O desvio é o tema recorrente nas veredas da memória e da linguagem. Quando imaginamos ter chegado a algo, este se nos escapa. Espécie de espelho melancólico da escrita. A memória revela-se involuntária, irreproduzível, incontrolável. Nossas certezas acerca da leitura acham-se então sepultadas, sob o túmulo e signo (sema) da linguagem rosiana. A escrita é antes o lugar de onde se desvia, do que a origem a que se encaminha, embalando tragicamente a memória. 
Diadorim dá a Riobaldo ocasião de examinar a fugacidade de todos os momentos, que apagam inapelavelmente os traços do companheiro amado. Em um momento, revela, em bela redondilha: "Despedir dá febre." (ROSA, 1994, p. 46) O narrador conhece assim o valor da saudade. Em cifra acentuadamente platônica, o amor erótico o eleva em direção a conjeturas ontológicas maiores. O que granjeia com isso, no entanto, não é a revelação do Ser, mas da fissura que o estilhaça, da perda ontológica: “o que é, é saudade.” (ROSA, 1994, p. 80) Nisso talvez resida uma das feições trágicas do romance. Goethe sugere residir na despedida (Abschied) a matriz de todos os eventos trágicos. Ele assim escreve:

\begin{abstract}
A motivação fundamental de todas as situações trágicas é o ato de partir [Abscheiden], e nesse caso não é preciso nem veneno nem punhal, nem lança nem espada; também é uma variação do mesmo tema o ato de se separar de uma situação habitual, amada, correta, seja por causa de uma calamidade maior ou menor, seja por causa de uma violência sofrida, que pode ser mais ou menos odiosa. (GOETHE apud SZONDI, 2004, p. 50)
\end{abstract}

O ser é configurado sob eterna despedida.Semelhante dialética sutil revela a tragicidade da perda: não apenas a vida, mas nós mesmos aparecemos como uma despedida adiada. Guimarães Rosa parece tê-lo assim compreendido quando escreveu: "A morte é corisco que sempre já veio." (ROSA, 1994, p. 240) A contradição se avizinha do indizível: lamentamos o "corisco da morte", o relampejar que assusta, que nos impõe a despedida, entretanto já a vivemos muitas outras vezes, pois "sempre já veio", evento que dá contorno à eternidade da perda, na iminência de tornar-se a perda da eternidade: uma eternidade inscrita na transitoriedade, que outra coisa seria senão sua mesma profanação?

Delineia-se assim um pensamento que segue a compreensão do ser na dimensão da ferida ontológica: "só é trágico o declínio de algo que não pode declinar, algo cujo desaparecimento deixa uma ferida incurável." (SZONDI, 2004, p. 85) Semelhante ferida (Wunde) que se esvai em cada gesto de despedida recebe nomes e ênfases variadas. No romance rosiano, inscreve-se nas saudades de Diadorim, sob cuja dor a narrativa vai-se tecendo não raro em modalidade trágica. Mesmo o lirismo tantas vezes encontrado nos aforismos com que o narrador desenha o perfil de Diadorim, silhueta certa tragicidade. $\mathrm{O}$ amor tem sido um assunto recorrente na lírica, o que sugere algumas perguntas: por que esse presença por vezes ostensiva, devido à sua delicadeza e fragilidade? Pela meditação acerca da subjetividade, sendo aquilo que expressa a fissura do sujeito, revelando o engodo da sua unidade? Por grassar o efêmero, a mudança? Afinal, o que seria o amor, senão o escândalo provocado pelo devir, a resistência e por vezes capitulação diante da transitoriedade?

Diadorim tem em seu nome o esfacelamento da memória. Seu tom erradio (día) oferta (dóros) apenas fragmentos de si e do passado. Por isso Riobaldo é cauteloso: "Qualquer amor já é um pouquinho de saúde, um descanso na loucura” (ROSA, 1994, p. 200), e adiante escreve: "Vivendo, se aprende; mas o que se aprende, mais, é só a fazer outras maiores perguntas." (ROSA, 1994, p. 264) Com seu percurso negativo e erradio, essa personagem ambígua aduz o entrelaçamento entre memória, amor e esperança no romance. Se a redenção não os alcança e unifica, é porque a linguagem, a exemplo de Diadorim, recusa qualquer reconciliação, o repouso da unidade. Nem a linguagem, nem Diadorim serão de Riobaldo, não se vergarão ao seu arbítrio. Durante a cena da anagnorisis, do reconhecimento prenhe de estranheza e ambiguidade do corpo do(a) amado(a), da sua revelação como mulher, tornando oblíqua toda a memória, todo o passado, Riobaldo diz: 
eu solucei meu desespero. A vida da gente nunca tem termo real. (...) E eu não sabia por que nome chamar; eu exclamei me doendo:

- "Meu amor!..."

Foi assim. Eu tinha me debruçado na janela, para poder não presenciar o mundo. (ROSA, 1994, p. 380)

O velho jagunço, no entanto, longe de exasperar-se, aceita o convívio da incerteza, afinal de contas até mesmo sobre si sabe muito pouco. Esse "si" é tão cambiante, que o desfecho da narração não se revela exatamente heroico; mais prenhe de incertezas, do que de arroubos corajosos. A sabedoria de Riobaldo revela-se então socrática apenas na aparência. A maiêutica nele esconde mais do que revela. A ignorância não é uma suspensão provisória do saber, mas a própria condição humana. Eis o máximo a que o aprendizado da memória pode conduzi-lo. É o momento em que Riobaldo pode confiar-nos alguns segredos, urdidos com silêncio e saudade.

Coutinho nota que essa passagem da descoberta do sexo de Diadorim constitui um dos pontos cruciais do romance, intimamente relacionada à questão do olhar. Mais especificamente, à relatividade dos sentidos (COUTINHO, 2013). É provocada por uma pergunta recorrente na narrativa, com a qual Riobaldo expressa a culpa por não haver sequer desconfiado da verdade por trás da aparência: "Como foi que não tive um pressentimento?" (ROSA, 1994, p. 125) Também presente com pequenas variações algumas páginas adiante: "Como é que eu ia poder ter pressentimento das coisas terríveis que vieram depois, conforme o senhor vai ver, que já lhe conto?” (ROSA, 1994, p. 184). Este quadro impreciso, ambíguo, que fez Riobaldo equivocar-se tantas vezes em sua leitura, explica algo da sedução provocada por essa narrativa. Sua articulação recorrentemente trágica das oposições que tece desconhece o desvelo por prover uma síntese mais abrangente. Semelhante síntese apenas se nomeia negativamente - ela é aquele nome de que a narrativa tantas vezes desconfia. Sua pulsação erótica a conduz não exatamente à scala amoris platônica, mas aos labirintos de uma saber a que a escrita fragmentária pode no máximo acenar.

\section{Referências bibliográficas}

ÁVILA, Afonso. Posfácio. In: NUNES, Benedito. “O amor na obra de Guimarães Rosa”. In: O dorso do tigre. São Paulo: Ed. 34, 2009.

AZEVEDO, Maria Teresa Schiappa. "Introdução". In: PLATÃO. O banquete. Trad. Maria Teresa Schiappa de Azevedo. LIsboa: Edições 70, 2010.

BENJAMIN, Walter. Origem do drama barroco alemão. Trad., apresentação e notas: Sergio Paulo Rouanet. São Paulo: Brasiliense, 1984.

BERNADETE, Seth. On Plato's Symposium. In: The argument of the action: essays on Greek poetry and philosophy. Edited with an introduction by Ronna Burger and Michael Davis. Chicago: The University of Chcago Press, 2000.

COUTINHO, Eduardo F. Grande sertão: veredas. Travessias. São Paulo: É Realizações, 2013.

FERrARI, G. R. F. Platonic love. In KRAUT, Richard. The Cambridge companion to Plato. Cambridge: Cambridge University Press, 1992. 2009.

FERREIRA, José Ribeiro. Introdução. In.: PLATÃO. Fedro. Trad. José Ribeiro Ferreira. Lisboa: Edições 70,

HACKFORTH, R. Introduction. In.: PLATO. Phaedrus. Trad. R. Hacforth. Cambridge: Cambridge University Press, 1952 (repr. 1997).

JAEGER, Werner. Paideia: a formação do homem grego. Trad. Artur M. Pereira. São Paulo: Martins Fontes, 
1995.

NIETZSCHE, Friedrich. "O caso Wagner”, §2. In: O caso Wagner: um problema para músicos / Nietzsche contra Wagner: dossiê de um psicólogo. Trad. Paulo César de Souza. São Paulo: Companhia das Letras, 1999.

NUNES, Benedito. "O amor na obra de Guimarães Rosa”. In: O dorso do tigre. São Paulo: Ed. 34, 2009.

NUSSBAUM, Martha. The speech of Alcibiades: a reading of the Symposium. In: The fragility of goodness: luck and ethics in Greek tragedy and philosophy. Cambridge: Cambridge University Press, 2001.

PLATÃo. O Banquete. Trad. Maria Teresa Schiappa de Azevedo. Lisboa: Edições 70, 2010.

Fedro. Trad. José Ribeiro Ferreira. Lisboa: Edições 70, 2009.

. Lisis. Trad. Francisco de Oliveira. Coimbra: Instituto Nacional de Investigação Científica, 1980.

REEVE, C. D. E. Plato on eros and friendship. In BENSON, Hugh H. A companion to Plato. Oxford: Blackwell Publishing, 2006.

ROSA, Guimarães. "Grande sertão: veredas". In: Fiç̧ão completa. Rio de Janeiro: Nova Aguilar, 1994. Vol.

SPERBER, Suzi Frank1. As palavras de chumbo e as palavras aladas. Floema - Ano II, n. 3, p. 137-157, jan./jun. 2006.

SZONDI, Peter. Ensaio sobre o trágico. Trad. Pedro Süssekind. Rio de Janeiro: Jorge Zahar Ed., 2004.

TRABATTONI, Franco. O amor platônico. Trad. Rineu Quinalia. São Paulo: Annablume, 2010. (Coleção Archai: as origens do pensamento ocidental, 2).

\section{Notas de fim}

1 Universidade Católica de Brasília e Universidade de Brasília. Pós-doutorando na Universidade de Coimbra (Bolsista Capes).

2 Tornou-se clássica a análise a que Augusto de Campos submeteu o nome "Diadorim", dividindo-o assim: a) Dia + adora + im; b) Diá + dor + im. A implicação que tira da análise é percuciente: "O que existe de ser e amor em Diadorim é representado pela vertente a) Dia + adora. O que há de não-ser, pela vertente b) Diá (diabo) + dor." (CAMPOS, 1991, p. 339). Não nos parece que as duas analises, a nossa e a de Augusto de Campos, excluem-se mutuamente. Revelam visadas diferentes. Mas num ponto se avizinham: o nome "Diadorim" é revelador das ambiguidades que vincam a personagem e, em grande medida, todo o Grande sertão. 